Short communication

\title{
Mercury profiles in sediments of the Pearl River Estuary and the surrounding coastal area of South China
}

\author{
Jian-bo Shi ${ }^{\text {a,b }}$, Carman C.M. Ip ${ }^{b}$, Gan Zhang ${ }^{c}$, Gui-bin Jiang ${ }^{\text {a }}$, Xiang-dong Li $^{\text {b,* }}$ \\ ${ }^{a}$ State Key Laboratory of Environmental Chemistry and Ecotoxicology, Research Center for Eco-Environmental Sciences, Chinese Academy of Sciences, P.O. Box 2871, \\ Beijing 100085, China \\ ${ }^{\mathrm{b}}$ Department of Civil and Structural Engineering, The Hong Kong Polytechnic University, Hung Hom, Kowloon, Hong Kong \\ 'State Key Laboratory of Organic Geochemistry, Guangzhou Institute of Geochemistry, Chinese Academy of Sciences, Guangzhou 510640, China \\ The spatial and historical changes of $\mathrm{Hg}$ in sediment reflect the industrial development and urbanization of the region in south China.
}

\section{A R T I C L E I N F O}

\section{Article history:}

Received 21 May 2009

Received in revised form

25 January 2010

Accepted 30 January 2010

\section{Keywords:}

Mercury

Sediment

Influx

${ }^{210} \mathrm{~Pb}$

Pearl River Estuary

South China

\begin{abstract}
A B S T R A C T
The spatial and temporal variations of mercury ( $\mathrm{Hg}$ ) in sediments of the Pearl River Estuary (PRE) and the surrounding coastal area (South China Sea) were studied. In surface sediments, the concentrations of Hg ranged from 1.5 to $201 \mathrm{ng} / \mathrm{g}$, with an average of $54.4 \mathrm{ng} / \mathrm{g}$, displaying a decreasing trend with the distance from the estuary to the open sea. This pattern indicates that the anthropogenic emissions from the Pearl River Delta (PRD) region are probably the main sources of $\mathrm{Hg}$ in this coastal region. Using the ${ }^{210} \mathrm{~Pb}$ dating technique, the historical changes in the concentrations and influxes of $\mathrm{Hg}$ in the last 100 years were also investigated. The variations in $\mathrm{Hg}$ influxes in sediment cores obviously correlate with the economic development and urbanization that has occurred the PRD region, especially in the last three decades.
\end{abstract}

(c) 2010 Elsevier Ltd. All rights reserved.

\section{Introduction}

The biogeochemistry of mercury $(\mathrm{Hg})$ in coastal and estuarial environments has been widely studied because of the high toxicity and biomagnification of this chemical element in the aquatic system (Mason et al., 1996; Horvat et al., 1999; Hines et al., 2000; Conaway et al., 2003; García-Rico et al., 2006). However, the biogeochemical cycles of $\mathrm{Hg}$ in different estuaries are variable and complicated due to the diverse input, physical, chemical, and hydrological conditions of $\mathrm{Hg}$. As a result, the behavior of $\mathrm{Hg}$ may differ from one estuary to another (Horvat et al., 1999; Conaway et al., 2003).

China plays an important role in global anthropogenic $\mathrm{Hg}$ emissions. Hg emissions in China were estimated to total approximately 696 tons in 2003, with an average rate of increase of $2.9 \%$ per year during the period 1995-2003 (Wu et al., 2006). A large amount of the $\mathrm{Hg}$ emissions obviously correlates with the rapid economic development that has taken place in the region during the last three decades. The increase in emissions of $\mathrm{Hg}$ has also caused the air, water, and soil in China to become seriously polluted (Feng, 2005; Jiang et al., 2006).

\footnotetext{
* Corresponding author. Tel.: +852 2766 6041; fax: +852 23346389 .

E-mail address: cexdli@polyu.edu.hk (X.D. Li).
}

The Pearl River Estuary (PRE), located in south China, is created by the inflows of fresh water to the South China Sea. The estuary covers an area of $8000 \mathrm{~km}^{2}$, with the distance from north to south averaging about $49 \mathrm{~km}$, and from east to west varying from 4 to $58 \mathrm{~km}$ (Zhang et al., 2003; Ip et al., 2004). The PRE has been found to be contaminated by a number of metal and organic pollutants, a result of the rapid urbanization and industrialization that has been occurring in the Pearl River Delta (PRD) region during the last a few decades (Hong et al., 1999; Fu et al., 2003; Ip et al., 2005; Liu et al., 2005; Mai et al., 2005; Chen et al., 2006). The PRD region, consisting of part of Guangdong Province as well as China's two special administrative regions of Hong Kong and Macao, is known as one of the most industrialized and urbanized regions in China. A large number of factories have been set up in the PRD region to produce a wide range of goods, including electronic products, medicines, cars, toys, clothing, and others. In 2002, exports from the PRD accounted for 35\% of China's total exports (Streets et al., 2006). Without effective treatment, the pollutants from the PRD would enter the PRE through direct discharge or with the run-off of river water. Several studies have demonstrated that PRE is the main reservoir of persistent organic pollutants, such as OCPs, PAHs, PCBs, and PBDEs (Chen et al., 2006; Guan et al., 2007, 2009). An estimated 23 metric tons of PBDEs have been discharged into the PRE in the 
last 20 years (Guan et al., 2007). Meanwhile, high concentrations of trace metals have also been found in the sediments and aquatic organisms of the PRE (Ip et al., 2005, 2006). However, Hg has largely been ignored in most studies of pollutants in the region, and thus the extent to which the PRE is contaminated with $\mathrm{Hg}$ is still unknown. Our previous investigation in Victoria Harbour, a part of the PRE, showed that the total Hg concentrations in surface sediments ranged from 47 to $855 \mathrm{ng} / \mathrm{g}$ (dry wt.), indicating the possible contamination of $\mathrm{Hg}$ in this area (Shi et al., 2007).

The aim of the present work was to study the spatial and temporal distribution of $\mathrm{Hg}$ in sediments of the PRE and its surrounding coastal area. Using the ${ }^{210} \mathrm{~Pb}$ dating technique, the historical changes in the concentrations and influxes of $\mathrm{Hg}$ in the last 100 years were also investigated.

\section{Materials and methods}

\subsection{Sample collection}

The map of the study area and the locations of the sampling sites are shown in Fig. 1. A total of 39 surface sediment samples were collected in September 2002. The sampling locations were distributed across the PRE and its surrounding coastal area. The surface sediments (top $10 \mathrm{~cm}$ ) were taken with a stainless steel grab sampler. Three sediment cores were also collected in this area in June 2000. The core sediments were taken using a gravity corer with an automatic clutch and reverse catcher. The diameters of the outside steel corer and the inside sampling PVC coring tube were 56 and $46 \mathrm{~mm}$, respectively. The sediment cores were sliced into $2 \mathrm{~cm}$ intervals from 0 to $50 \mathrm{~cm}$ and into $4 \mathrm{~cm}$ intervals from $50 \mathrm{~cm}$ to the end of the cores.

All of the samples were stored in polyethylene bags at $4-6{ }^{\circ} \mathrm{C}$ immediately after collection. In the laboratory, the sediments were freeze-dried at $-45^{\circ} \mathrm{C}$ for 3 days and then ground in an agate grinder until fine particles were obtained.

\subsection{Determination of $\mathrm{Hg}$ in sediments}

To analyze the total amount of $\mathrm{Hg}$ present in the samples, about $0.25 \mathrm{~g}$ of grounded sediment samples were digested with $5 \mathrm{~mL}$ of aqua regia in an AIM 500 Automated Block Digestion System (A.I. Scientific Pty Ltd, Australia) at $95{ }^{\circ} \mathrm{C}$ for $2 \mathrm{~h}$ and shaken frequently. After cooling down, the solutions were diluted to $25 \mathrm{~mL}$ with Milli-Q water and then centrifuged at $3000 \mathrm{rpm}$ for $15 \mathrm{~min}$. The $\mathrm{Hg}$ concentrations were determined by the Flow Injection Mercury System (FIMS, Perkin Elmer) using $\mathrm{SnCl}_{2}$ for the reduction step.

For the analytical quality control, reagent blanks, certified reference materials (CRMs), and sample replicates were randomly inserted in the analysis. The determined concentrations of $\mathrm{Hg}$ in two sediment CRMs (36 $\pm 2 \mathrm{ng} / \mathrm{g}$ in NIST 1646a and $282 \pm 8 \mathrm{ng} / \mathrm{g}$ in GBW07310, $n=4$ ) were both in good agreement with their certified

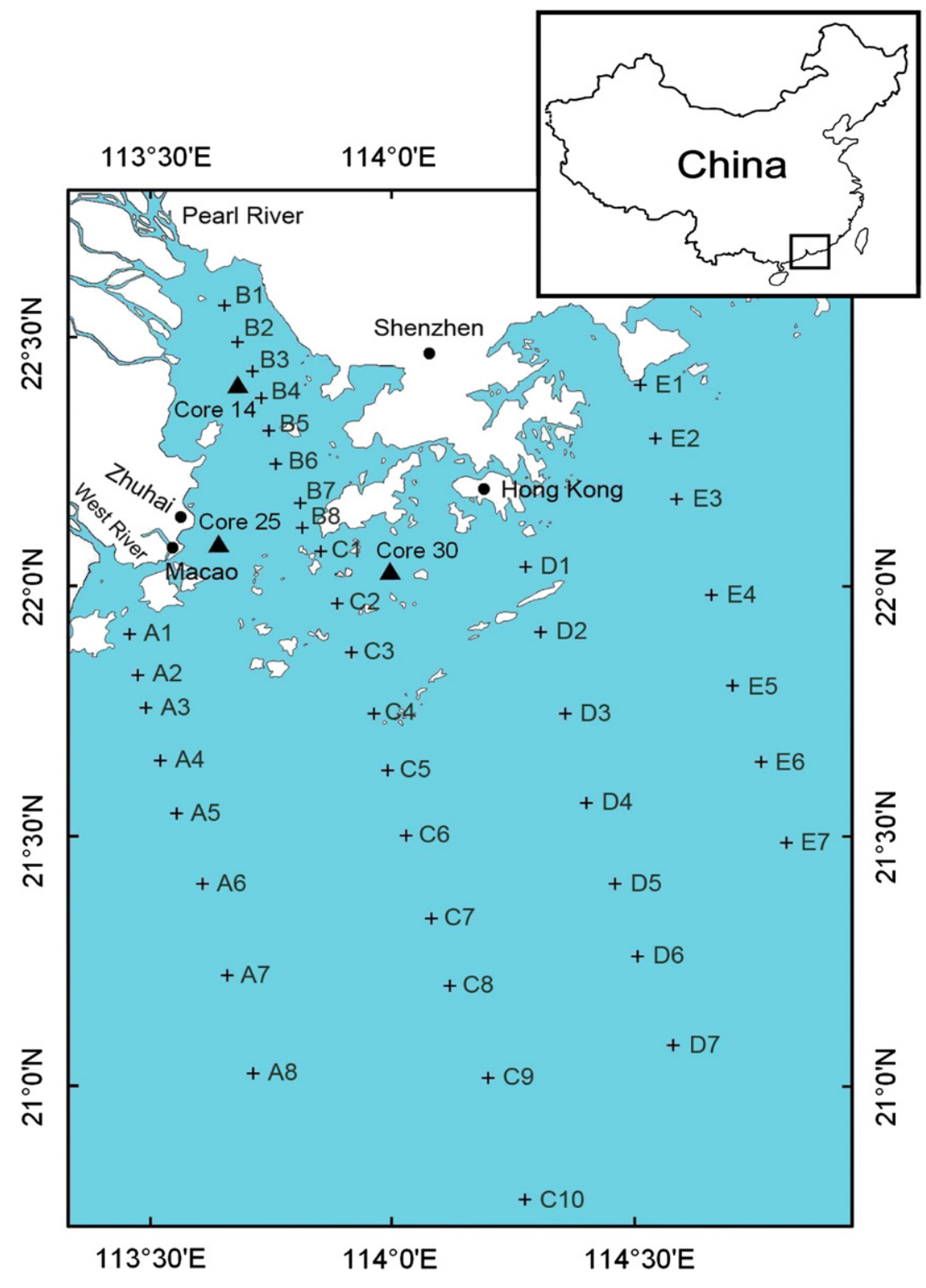

Fig. 1. Map of the study area. 


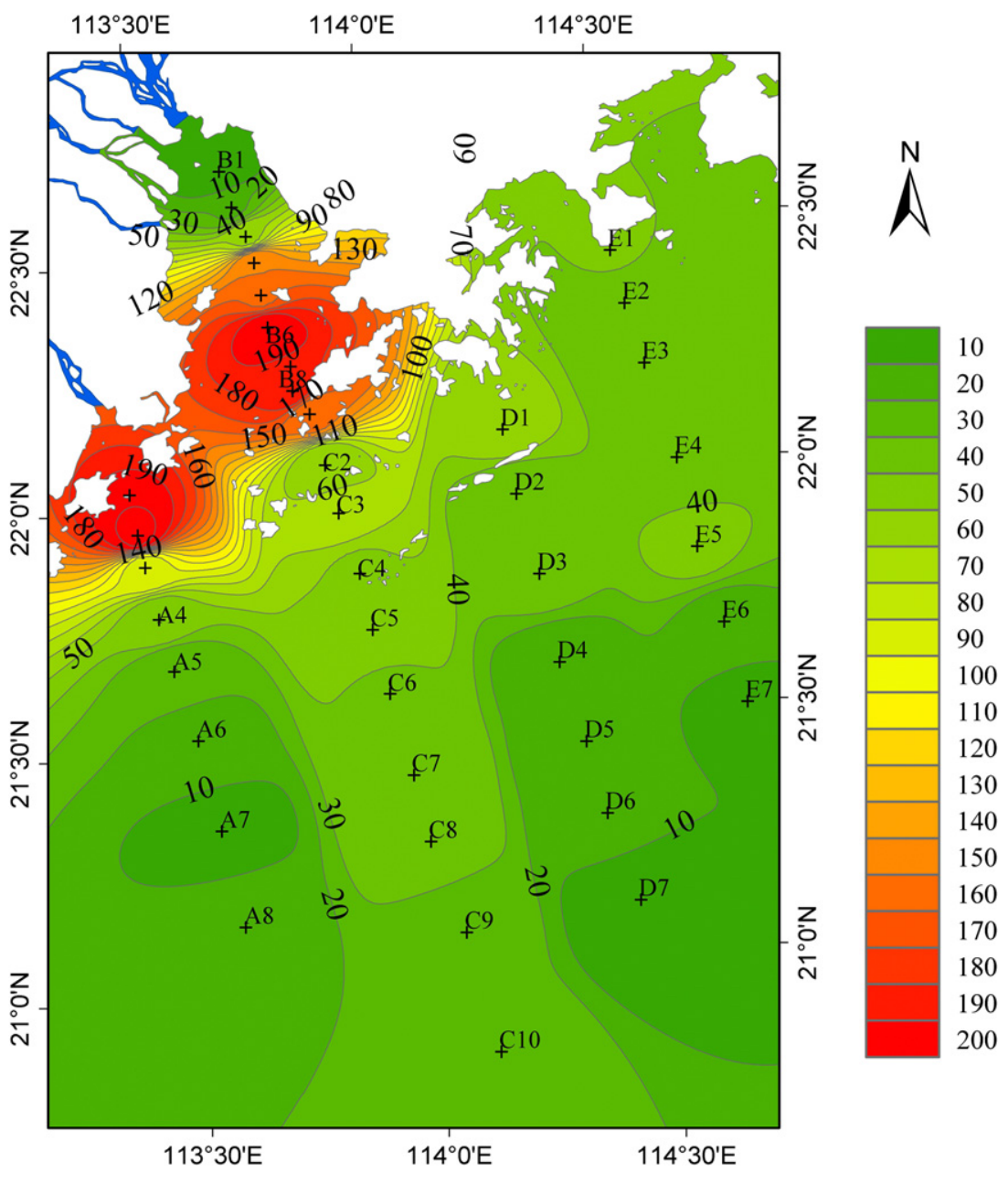

Fig. 2. The spatial distribution of $\mathrm{Hg}$ in surface sediments.

values ( $40 \mathrm{ng} / \mathrm{g}$ in NIST 1646a and $280 \pm 40$ in GBW07310), indicating the method was accurate and reliable.

\section{3. ${ }^{210} \mathrm{~Pb}$ dating}

The ${ }^{210} \mathrm{~Pb}$ radiometric technique was used to estimate the chronology of the sediment cores. A constant rate of the ${ }^{210} \mathrm{~Pb}$ supply (CRS) model was applied to date the sediment cores, to obtain sediment influxes over time (McCall et al., 1984). The detailed method and results of ${ }^{210} \mathrm{~Pb}$ dating have been described elsewhere (Ip et al., 2004).

\subsection{Geochemical mapping}

The concentrations of $\mathrm{Hg}$ were used as the input data for grid-based contour mapping, to study the spatial distribution of $\mathrm{Hg}$ in the PRE and its surrounding coastal area. The software used was ArcGIS 8.2, and the Inverse Distance Weighted (IDW) method was adopted for the interpolation of the geochemical data.

\section{Results and discussion}

\subsection{Spatial distribution}

The concentrations of $\mathrm{Hg}$ in surface sediments ranged from 1.5 to $201 \mathrm{ng} / \mathrm{g}$. The average and median concentrations were 54.4 and $36.2 \mathrm{ng} / \mathrm{g}$, respectively. The geochemical map of $\mathrm{Hg}$ in the study area is shown in Fig. 2. The spatial distribution of $\mathrm{Hg}$ was similar with those of $\mathrm{Cu}, \mathrm{Zn}$, and $\mathrm{Pb}$ (Ip et al., 2006), displaying a decreasing pattern with increasing distance from the estuary to the open sea. This indicates that anthropogenic emissions from the PRD are probably the main sources of $\mathrm{Hg}$ in the sediments of the PRE and its surrounding coastal area. Although it had been thought that the outflow of the Pearl River is the most important source of $\mathrm{Hg}$ in the estuary, the concentrations of $\mathrm{Hg}$ in sediments near the end of the Pearl River were relatively low. By contrast, two hotspots were found at the mouth of the PRE and the northwest part of the coastal zone, a sign of the influence of the discharge of waste from the coastal cities, and the circulation currents in the estuary.

Table 1 shows the content of $\mathrm{Hg}$ in different marine sediments. Compared with the reported background total $\mathrm{Hg}$ levels in marine sediments (50-80 ng/g, (Fujii, 1976); 20-100 ng/g, (Lindqvist et al., 1984)), the sediments collected from the PRE were significantly

Table 1

Comparison of the concentrations of $\mathrm{Hg}$ in different marine sediments.

\begin{tabular}{lll}
\hline Location & $\mathrm{Hg}(\mathrm{ng} / \mathrm{g})$ & Reference \\
\hline The Arctic Ocean Basin & $10-116$ & (Gobeil et al., 1999) \\
South Florida Estuaries, USA & $20(1-219)$ & (Kannan et al., 1998) \\
$\begin{array}{l}\text { The East China Sea, China } \\
\text { Malaysian coast, Malaysia }\end{array}$ & $37(<0.5-80)$ & (Shi et al., 2005) \\
& $61(20-127)$ & $\begin{array}{l}\text { (Kannan and Falandysz, } \\
\text { 1998) }\end{array}$ \\
$\begin{array}{l}\text { San Francisco Bay, USA } \\
\text { Anadyr Estuary, Russia }\end{array}$ & $201(20-702)$ & $\begin{array}{l}\text { (Conaway et al., 2003) } \\
\text { (Kannan and Falandysz, }\end{array}$ \\
$\begin{array}{ll}\text { Seine Estuary, France } \\
\text { The PRE and coastal area, } \\
\text { South China }\end{array}$ & $539(77-2100)$ & $\begin{array}{l}\text { 1998) } \\
\text { (Mikac et al., 1999) }\end{array}$ \\
\hline
\end{tabular}


Hg concentation $(\mathrm{ng} / \mathrm{g})$

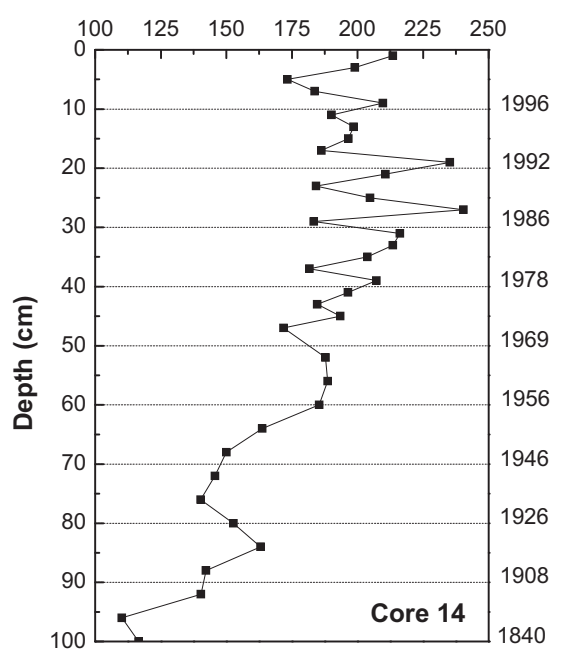

Hg concentration (ng/g)

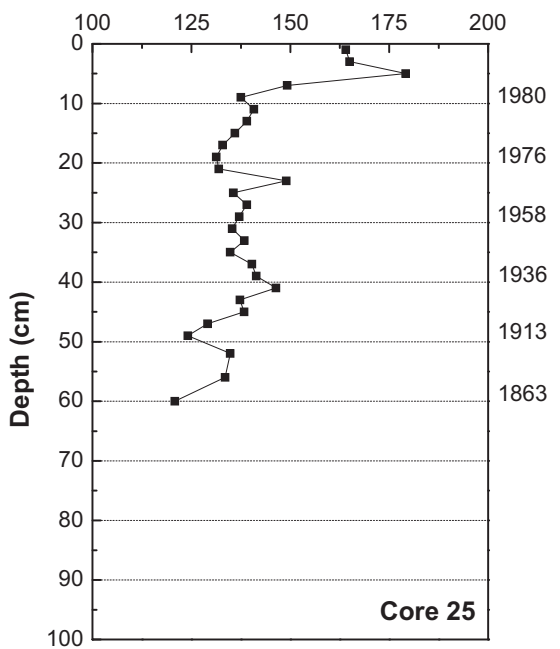

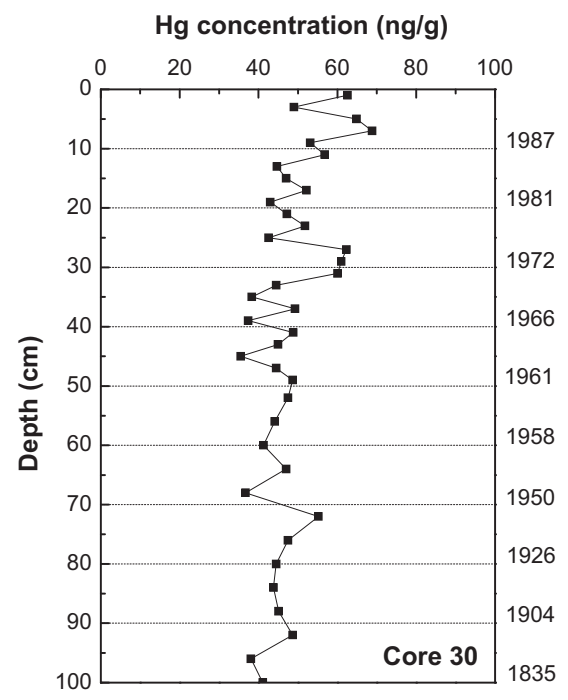

Fig. 3. The vertical distribution of $\mathrm{Hg}$ in sediment cores.

contaminated with $\mathrm{Hg}$. However, the concentrations of $\mathrm{Hg}$ in most sediments from the coastal area were still within the background range ( $<80 \mathrm{ng} / \mathrm{g}$, see Fig. 2). As a whole, the concentrations of $\mathrm{Hg}$ in the study area were higher than those in sediments from the Arctic Ocean Basin, South Florida Estuaries (USA), and the East China Sea (China), but lower than those in the Malaysian coast (Malaysia), San Francisco Bay (USA), Anadyr Estuary (Russia), and Seine Estuary (France).

\subsection{Temporal distribution}

Three sediment cores were collected from the study area and dated using the ${ }^{210} \mathrm{~Pb}$ technique. The vertical distributions of $\mathrm{Hg}$ in sediment cores and the year in which they are estimated to have become present are shown in Fig. 3. Cores 14 and 25 are located around the two zones with high concentrations of $\mathrm{Hg}$. Core 30 is located in the South China Sea outside the PRE and close to Hong Kong. Therefore, the concentrations of $\mathrm{Hg}$ in cores 14 and 25 were significantly higher than those in core 30 . In core 14 , the concentrations of $\mathrm{Hg}$ were relatively higher in the upper $45 \mathrm{~cm}$, corresponding to the period from 1972 to the present, and then decreased with the depth in the rest of the core. The concentrations of $\mathrm{Hg}$ in core 25 decreased slightly with depth in the profile, but were significantly high in the top $10 \mathrm{~cm}$ of sediments (after 1980). In these two cores, the concentrations of $\mathrm{Hg}$ in the sediments of the PRE increased during the last century, especially in the last 2-3 decades. However, in core 30, the change in $\mathrm{Hg}$ concentrations with depth was not significant, except that the concentrations of $\mathrm{Hg}$ in 5-7 cm (1990-1993) and 27-31 cm (1970-1974) were slightly higher than in other layers.

\subsection{Influx of $\mathrm{Hg}$}

In order to identify the influence of anthropogenic inputs, the influxes of $\mathrm{Hg}$ in the sediment cores were calculated. The influxes of $\mathrm{Hg}$ for decade $j$ in sediment core $i$ were calculated using the following equation (Yang et al., 2002):

Influx $=\sum A_{i} \rho_{i t} D_{i t} C_{i t}$,

where $A_{i}$ is the area of the sediment core $\left(\mathrm{cm}^{2}\right), \rho_{i t}$ is the sediment dry density for interval $t$ (e.g., decade) $\left(\mathrm{g} / \mathrm{cm}^{3}\right), D_{i t}$ is the thickness of 
Influx of $\mathrm{Hg}$ ( $\left.\mathrm{ng} / \mathrm{cm}^{2} / \mathrm{decade}\right)$

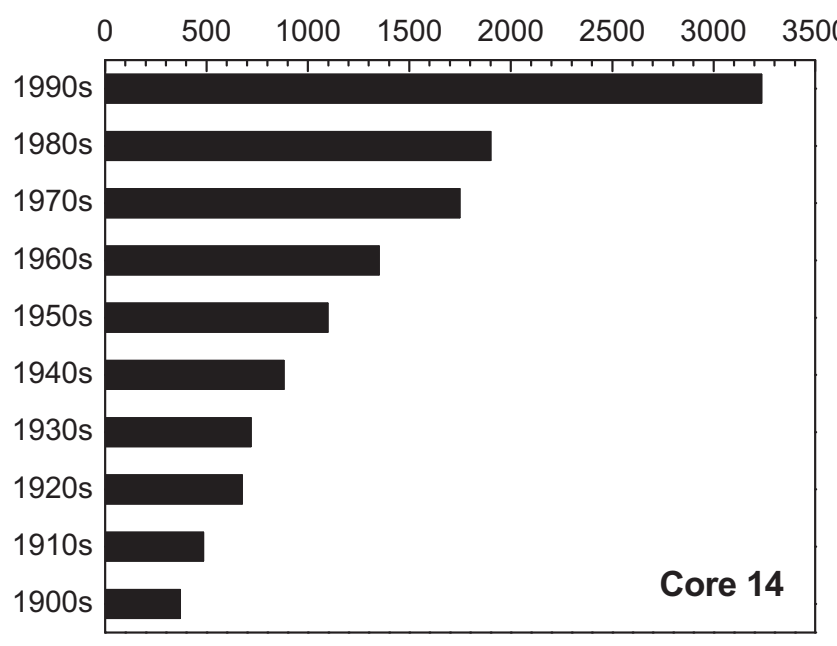

Influx of $\mathrm{Hg}\left(\mathrm{ng} / \mathrm{cm}^{2} /\right.$ decade)

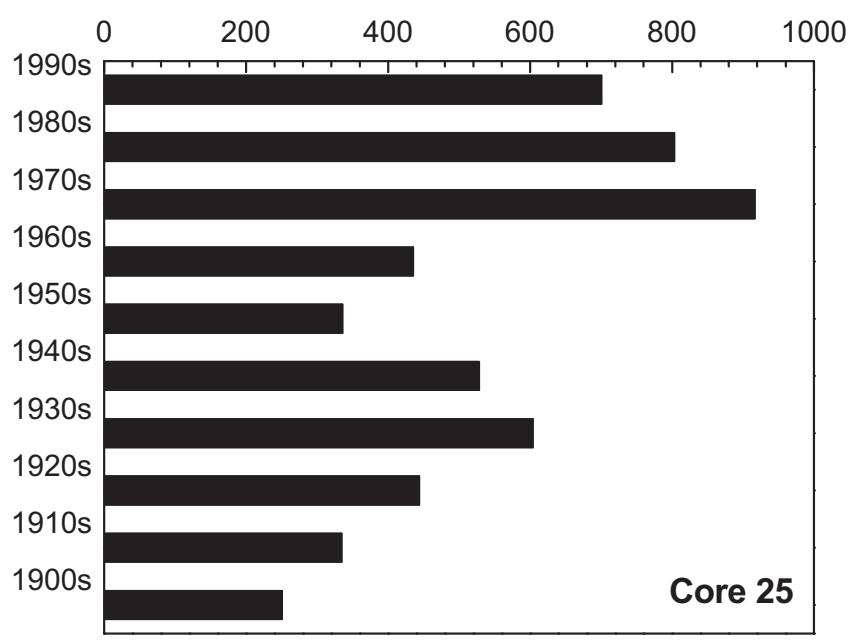

Influx of $\mathrm{Hg}\left(\mathrm{ng} / \mathrm{cm}^{2} / \mathrm{decade}\right)$

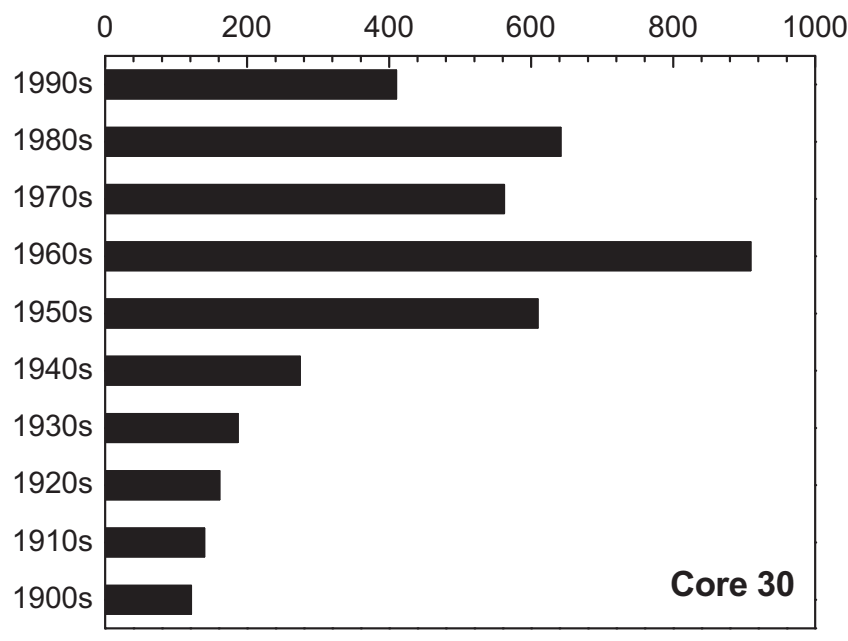

Fig. 4. The influxes of $\mathrm{Hg}$ in sediment profiles. the sediment for interval $t$ within decade $j$ in core $i(\mathrm{~cm})$, and $C_{i t}$ is the concentration of $\mathrm{Hg}$ for interval $t(\mathrm{ng} / \mathrm{g})$. The changes of $\mathrm{Hg}$ influxes in sediment cores in the last 100 years are shown in Fig. 4. The influxes of $\mathrm{Hg}$ in core 14 increased gradually in the last century, but rapidly after the 1970s, especially in the 1990s. The influx of $\mathrm{Hg}$ in the 1990s was approximately 9 times that in the 1900s and 3 times that in the 1950s. In core 25, high influxes of $\mathrm{Hg}$ were also found after the 1970s, despite a small reduction in the 1980s and 1990s. The increase in influxes of $\mathrm{Hg}$ in cores 14 and 25 obviously correlates with the economic development and urbanization of the PRD region, especially in the last three decades. In core 30 , which is located outside of the PRE, the influx of $\mathrm{Hg}$ increased from the 1950 s and peaked in the 1960s. The influx of $\mathrm{Hg}$ in the 1990s was only $45 \%$ of that in the 1960 s and even less than that in the 1950 s. This showed that the $\mathrm{Hg}$ in this core probably came from discharges related to Hong Kong, because the development of Hong Kong's industry started in the 1950s and rapidly increased in the 1960s and 1970s. During this period, a large number of factories were established, which produced basic industrial chemicals, paints, electroplating, enamelware, batteries, and so forth. In the early 1980s, many factories were moved to mainland China, and industrial activities in the territory declined significantly in the last few decades. Meanwhile, since the 1980s, the Hong Kong government has made efforts to put in place some strict controls over the discharge of pollutants (Shi et al., 2007).

\section{Conclusions}

The concentrations of $\mathrm{Hg}$ in surface sediments of the PRE and the surrounding coastal area decreased with the increasing distance from the estuary to the open sea, indicating that the $\mathrm{Hg}$ contamination was mainly caused by anthropogenic emissions from the PRD region. By using the ${ }^{210} \mathrm{~Pb}$ dating technique, the historical changes in the concentrations and influxes of $\mathrm{Hg}$ in sediment cores in the last 100 years were revealed. The influxes of $\mathrm{Hg}$ in sediments were found to significantly correlate with the economic development and urbanization that has taken place in the PRD region, especially in the last three decades.

\section{Acknowledgments}

The work described here was supported by the Research Grants Council of the Hong Kong SAR Government (PolyU 5212/05E and N_PolyU 535/05), the Area of Excellence Scheme under the University Grants Committee of the Hong Kong SAR Government (AoE/P04/2004), and the National Natural Science Foundation of China (20807047).

\section{References}

Chen, S.J., Luo, X.J., Mai, B.X., Sheng, G.Y., Fu, J.M., Zeng, E.Y., 2006. Distribution and mass inventories of polycyclic aromatic hydrocarbons and organochlorine pesticides in sediments of the Pearl River Estuary and the northern South China Sea. Environmental Science \& Technology 40, 709-714.

Conaway, C.H., Squire, S., Mason, R.P., Flegal, A.R., 2003. Mercury speciation in the San Francisco Bay estuary. Marine Chemistry 80, 199-225.

Feng, X.B., 2005. Mercury pollution in China - an overview. In: Pirrone, N., Mahaffey, K. (Eds.), Dynamics of Mercury Pollution on Regional and Global Scale: Atmospheric Process, Human Exposure Around the World. Springer Publishers, Norwell, MA, pp. 657-678.

Fu, J.M., Mai, B.X., Sheng, G.Y., Zhang, G., Wang, X.M., Peng, P.A., Xiao, X.M., Ran, R., Cheng, F.Z., Peng, X.Z., Wang, Z.S., Tang, U.W., 2003. Persistent organic pollutants in environment of the Pearl River Delta, China: an overview. Chemosphere 52, 1411-1422.

Fujii, M., 1976. Mercury Distribution in Lithosphere and Atmosphere. Kodansha Scientific, Tokyo.

García-Rico, L., Rodríguez, M.V., Jara-Marini, M.E., 2006. Geochemistry of mercury in sediment of oyster areas in Sonora, Mexico. Marine Pollution Bulletin 52, 447-469. 
Gobeil, C., Macdonald, R.W., Smith, J.N., 1999. Mercury profiles in sediments of the Artic Ocean Basins. Environmental Science \& Technology 33, 4194-4198.

Guan, Y.F., Wang, J.Z., Ni, H.G., Luo, X.J., Mai, B.X., Zeng, E.Y., 2007. Riverine inputs of polybrominated diphenyl ethers from the Pearl River Delta (China) to the coastal ocean. Environmental Science \& Technology 41, 6007-6013.

Guan, Y.F., Wang, J.Z., Ni, H.G., Zeng, E.Y., 2009. Organochlorine pesticides and polychlorinated biphenyls in riverine runoff of the Pearl River Delta, China: assessment of mass loading, input source and environmental fate. Environmental Pollution 157, 618-624.

Hines, M.E., Horvat, M., Faganeli, J., Bonzongo, J.-C.J., Barkay, T., Major, E.B., Scott, K.J., Bailey, E.A., Warwick, J.J., Lyons, W.B., 2000. Mercury biogeochemistry in the Idrija River, Slovenia, from above the mine into the Gulf of Trieste. Environmental Research Section A 83, 129-139.

Hong, H.S., Chen, W.Q., Xu, L., Wang, X.H., Zhang, L.P., 1999. Distribution and fate of organochlorine pollutants in the Pearl River Estuary. Marine Pollution Bulletin 39, 376-382.

Horvat, M., Covelli, S., Faganeli, J., Logar, M., Mandić, V., Rajar, R., Širca, A., Žagar, D., 1999. Mercury in contaminated coastal environments; a case study: the Gulf of Trieste. Science of the Total Environment 237/238, 43-56.

Ip, C.C.M., Li, X.D., Zhang, G., Farmer, J.G., Wai, O.W.H., Li, Y.S., 2004. Over one hundred years of trace metal fluxes in the sediments of the Pearl River Estuary, South China. Environmental Pollution 132, 157-172.

Ip, C.C.M., Li, X.D., Zhang, G., Wai, O.W.H., Li, Y.S., 2006. Trace metal distribution in sediments of the Pearl River Estuary and the surrounding coastal area, South China. Environmental Pollution 147, 311-323.

Ip, C.C.M., Li, X.D., Zhang, G., Wong, C.S.C., Zhang, W.L., 2005. Heavy metal and Pb isotopic compositions of aquatic organisms in the Pearl River Estuary, South China. Environmental Pollution 138, 494-504.

Jiang, G.B., Shi, J.B., Feng, X.B., 2006. Mercury pollution in China. Environmenta Science \& Technology 40, 3673-3678.

Kannan, K., Falandysz, J., 1998. Speciation and concentrations of mercury in certain coastal marine sediment. Water, Air, and Soil Pollution 103, 129-136.

Kannan, K., Smith, J.R.G., Lee, R.F., Windom, H.L., Heitmuller, P.T., Macauley, J.M. Summers, J.K., 1998. Distribution of total mercury and methyl mercury in water sediment and fish from South Florida Estuaries. Archives of Environmental Contamination and Toxicology 34, 109-118.
Lindqvist, O., Jernelöv, A., Johansson, K., Rohde, H., 1984. Mercury in the Swedish Environment. Global and Local Sources. National Swedish Environmental Protection Board.

Liu, G.Q., Zhang, G., Li, X.D., Li, J., Peng, X.Z., Qi, S.H., 2005. Sedimentary record of polycyclic aromatic hydrocarbons in a sediment core from the Pearl River Estuary, South China. Marine Pollution Bulletin 51, 912-921.

Mai, B.X., Zeng, E.Y., Luo, X.J., Yang, Q.S., Zhang, G., Li, X.D., Sheng, G.Y., Fu, J.M., 2005. Abundances, depositional fluxes, and homologue patterns of polychlorinated biphenyls in dated sediment cores from the Pearl River Delta, China. Environmental Science \& Technology 39, 49-56.

Mason, R.P., Reinfelder, J.R., Morel, F.M.M., 1996. Uptake, toxicity, and trophic transfer of mercury in a coastal diatom. Environmental Science \& Technology 30, 1835-1845.

McCall, P.L., Robins, J.A., Matisoff, G., 1984. Cs-137 and Pb-210 transport and geochronologies in urbanized reservoirs with rapidly increasing sedimentationrates. Chemical Geology 44, 33-65.

Mikac, N., Niessen, S., Ouddane, B., Wartel, M., 1999. Speciation of mercury in sediments of the Seine Estuary (France). Applied Organometallic Chemistry 13, 715-725.

Shi, J.B., Ip, C.C.M., Tang, C.W.Y., Zhang, G., Wu, R.S.S., Li, X.D., 2007. Spatial and temporal variations of mercury in sediments from Victoria Harbour, Hong Kong. Marine Pollution Bulletin 54, 480-485.

Shi, J.B., Liang, L.N., Yuan, C.G., He, B., Jiang G.B., 2005. Methylmercury and total mercury in sediment collected from the East Chia Sea. Bulletin of Environmental Contamination and Toxicology 74, 980-987.

Streets, D.G., Yu, C., Bergin, M.H., Wang, X.M., Carmichael, G.R., 2006. Modeling study of air pollution due to the manufacture of export goods in China's Pearl River Delta. Environmental Science \& Technology 40, 2099-2107.

Wu, Y., Wang, S.X., Streets, D.G., Hao, J.M., Chan, M., Jiang, J.K., 2006. Trends in anthropogenic mercury emissions in China from 1995 to 2003. Environmental Science \& Technology 40, 5312-5318.

Yang, H., Rose, N.L., Battarbee, R.W., Boyle, J.F., 2002. Mercury and lead budgets for Lochnagar, a Scottish mountain lake and its catchment. Environmental Science \& Technology 36, 1383-1388.

Zhang, G., Yan, J., Fu, J.M., Parker, A., Li, X.D., Wang, Z.S., 2003. Butyltins in sediments and biota from the Pearl River Delta, South China. Chemical Speciation and Bioavailability $14,35-42$. 